\title{
Relation between Cor Pulmonale Status and Metrics of Six Minute Walk Test in Patients with Chronic Obstructive Pulmonary Disease: A Cross Sectional Study
}

\section{Atefeh Fakharian, Shahram Kharabian Masouleh* and Tayebeh Farhadi}

Chronic Respiratory Diseases Research Center (CRDRC), National Research Institute of Tuberculosis and Lung Diseases (NRITLD), Shahid Beheshti University of Medical Sciences, Tehran, Iran

*Corresponding author: Masouleh SK, Chronic Respiratory Diseases Research Center (CRDRC), National Research Institute of Tuberculosis and Lung Diseases (NRITLD), Shahid Beheshti University of Medical Sciences, Tehran, Iran, Tel: +982127122035; E-mail: drshahramkh@gmail.com

Rec date: Jun 24, 2017; Acc date: Jul 18, 2017; Pub date: Jul 25, 2017

Copyright: (c) 2017 Masouleh SK, et al. This is an open-access article distributed under the terms of the Creative Commons Attribution License, which permits unrestricted use, distribution, and reproduction in any medium, provided the original author and source are credited.

Citation: Fakharian A, Masouleh SK, Farhadi T (2017) Relation between cor pulmonale status and metrics of six minute walk test in patients with chronic obstructive pulmonary Disease: A cross sectional study. Chron Obstruct Pulmon Dis Vol No 2 Iss No 1: 25.

\section{Abstract}

Background: Cor pulmonale is a complication of chronic obstructive pulmonary disease (COPD). The use of the six minute walk test (6MWT) to discriminate between COPD patients with and without cor pulmonale remains unclear.

Objectives: To study whether the existence of cor pulmonale in COPD is related to characteristic findings in distance and desaturation in 6MWT.

Material and Methods: Patients with confirmed COPD who were referred to rehabilitation unit of Masih Daneshvari hospital were studied. Subjects were categorized into cor pulmonale and non cor pulmonale according to physical examination and echocardiography findings. Standard 6MWT was performed according to published statements. The covered distance and the amount of oxygen desaturation were recorded. Comparisons between the two groups were conducted in two-tailed using Mann-Whitney tests.

Result: A total of 101 patients were evaluated ( 78 male and 23 female). There were 49 cor pulmonale (48.5\%) and 52 non cor pulmonale $(51.5 \%)$ with a mean age of $59.98 \pm$ 15.92 and $51.88 \pm 19.04$ ( $p>0.05$ ), respectively. The mean of 6MWT distance in patients with and without cor pulmonale were $264.85 \pm 114.1$ meters and $344.13 \pm 84.19$ meters, respectively $(p<0.05)$. Oxygen desaturation in cor pulmonale and non-cor pulmonale patients were $8.71 \pm 6.41 \%$ and $7.90 \pm 6.80 \%$, respectively ( $p>0.05)$.

Conclusion: The distance covered by cor pulmonale subjects in 6MWT is significantly less than non cor pulmonale. However, despite the oxygen desaturation in both groups, there is no significant difference between two groups.

Keywords: Chronic obstructive pulmonary disease; Six minute walk test; Cor pulmonale

\section{Introduction}

Chronic obstructive pulmonary disease (COPD) is one of the most important reasons for disability and death in patients with moderate to severe airways obstruction. The disease has been known as the third-most common cause of death in the worldwide [1]. It has shown that the prevalence of COPD in Iran is about $5.57 \%$ and it is on the rise [2]. Cor pulmonale refers to pulmonary hypertension ( $\mathrm{PHtn}$ ) response and is a consequence of hypoxic respiratory diseases and generally. Functional or structural abnormalities of the heart that are secondary to dysfunction of the endothelial of pulmonary vessels as well as proliferation of smooth muscle can lead to Cor pulmonale $[3,4]$. The exact prevalence of cor pulmonale in COPD is unknown but a wide range between $20-91 \%$ has been estimated based on the severity of COPD $[5,6]$. Besides, the cor pulmonale, which is routinely a consequence of COPD, has been reported to be a cause of 10 to $30 \%$ of heart failure admissions in the United States [7]. It has been shown that Cor pulmonale reduces the survival rate of affected subjects significantly. The mean survival of COPD patients with and without clinical signs and symptoms of Cor pulmonale is estimated to be seven and 13.5 years, respectively [8-11]. Hence, early detection of Cor pulmonale is essential and the involved patients need more diagnostic evaluation as well as special attention.

Some investigations including echocardiography, arterial blood gas measurement, lung biopsy, right heart catheterization and exercise stress test are the important items that have been involved in the diagnosis and evaluation of Cor pulmonale [4]. Various laboratory-based exercise stress tests are developed to investigate the impact of the disease on the patient's functional capacity (FC) and disability. Despite of the quite accuracy of laboratory-based exercise tests, their cost is very high that consequently limits the application of such tests. Field exercise tests are considered as the alternatives to laboratory-based exercise tests. They have some advantages since they are cheaper than laboratory-based exercise tests and can be carried out using easily accessible instruments. It has been widely accepted that the FC estimated by using the field tests, is same as the measured FC using a laboratory-based exercise test [4]. 
Six-minute walk test (6MWT) is one of the well-established field tests and is a simple, objective, reproducible and clinically relevant test. It has been developed to evaluate the patients' FC and its utilization has been validated in different clinical conditions such as cardio respiratory diseases [12]. In the recent years, 6MWT has been also used to evaluate and follow up patients with primary and secondary $\mathrm{PHtn}$ after their treatment $[13,14]$. In this test, a subject walks back and forth in a corridor as far as possible in six minutes. The distance covered by the patient is a primary measurement and is correlated with the patients FC. In various studies, this test has been accepted as an index to grade the severity of the disease in COPD patients as well as candidates for the lung transplantation [12]. For many years, the importance of the oxygen desaturation during 6MWT was unknown. Therefore, in a statement proposed by American Thoracic Society (ATS) in 2002, oxygen saturation $\left(\mathrm{SPO}_{2}\right)$ monitoring during 6MWT was not stated as a standard procedure [15-17]. More recent trials have shown that there is a tendency between levels of the oxygen desaturation during the 6MWT and the degree of the heart and respiratory performance $[18,19]$. Accordingly, European Respiratory Society (ERS) and ATS proposed the continue monitoring of the oxygen as a standard procedure during the $6 \mathrm{MWT}$ in the official field test $[20,21]$.

Despite of a high prevalence of COPD in Iran, few studies have focused on the results of 6MWT in these patients. In this study, it was attempt to investigate the impact of cor pulmonale in COPD patients by checking both $\mathrm{SPO}_{2}$ and distance during 6MWT.

\section{Material and methods}

\section{Study population}

This study is a cross sectional study that was carried out between November 2015 and September 2016. Patients with confirmed COPD who were referred to the pulmonary rehabilitation unit of Masih Daneshvari hospital, were involved in the study. Masih Daneshvari hospital is a tertiary center for respiratory diseases in Tehran, Iran. The non-Cor pulmonale group contained the subjects with COPD that had not a physical examination and/or echocardiography evidence of PHtn. Written informed consent was obtained from each patient prior to the participation. The exclusion criteria of the study included those with (1) previous lower extremity trauma, (2) preliminary metabolic diseases such as hypothyroidism and diabetes mellitus (DM), (3) renal impairments and (4) previous ischemic heart disease (IHD).

\section{Physical and history questionnaire}

Documents including medical history, physical examination, pulmonary function test and echocardiography were obtained and participants were accordingly categorized into Cor pulmonale and non-Cor pulmonale groups.

The physical examination findings evaluated in the study include ankle edema and prominent jugular vein. The echocardiography findings include the dilated right ventricle, tricuspid valve regurgitation and elevated pulmonary artery pressure. The Participants that showed one of these criteria were grouped as Cor pulmonale.

Here, in order to avoid errors and forms of misclassification bias, the authors utilized the data of the physical exams that were collected by others. This may be a form of bias that includes misclassification.

\section{Walking measurement}

The standard 6MWT was performed for all subjects according to the ATS statement [15]. Patients were excluded from the $6 \mathrm{MWT}$ if they had unstable angina or myocardial infarction in a previous month, resting heart rate $\geq 120$, systolic blood pressure $\geq 180 \mathrm{mmHg}$, diastolic blood pressure $\geq 100 \mathrm{mmHg}$ and superficial oxygen saturation $\left(\mathrm{SpO}_{2}\right) \leq 88 \%$. The test was done along a flat and straight corridor (length: 30 meter). Prior to the test, each patient sat on a chair located close to the start line and was relaxed for at least $20 \mathrm{~min}$. Then, a well-trained technician explained the process of $6 \mathrm{MWT}$ to the patients. The patients were asked to walk as far as possible for six minutes. The lap counter was set to zero and the timer was set to six minutes. The number of laps was recorded. The total distance walked was calculated rounding to the nearest meter, and recorded on the worksheet. In the case of intolerable shortness of breath or fatigue, subjects were allowed to rest while the timer was not stopped. If the participants felt chest pain, severe dyspnea, severe fatigue, staggering or severs calf pain at any time the test was terminated. At the end of the six minutes, the covered distance (in meter) and patients' heart rate were measured.

\section{Oxygen saturation measures}

Patients' heart rate, blood pressure, and $\mathrm{SPO}_{2}$ were measured with a pulse oxymeter probe (OXYCOUNT Mini-WeinmannGermany) from their right index finger. During the test, $\mathrm{SPO}_{2}$ was automatically recorded every 30 seconds. $\mathrm{SPO}_{2}$ was recorded as the percentage of the oxygen saturation. To calculate the differences of the $\mathrm{SPO}_{2}$, the $\mathrm{SPO}_{2}$ that was recorded before the test was compared to the $\mathrm{SPO}_{2}$ measured at the end of the test. The $\mathrm{SPO}_{2}$ difference was also reported in percentage.

For statistical analysis, SPSS 11 software was used. Results were expressed as a mean \pm standard deviation (SD). Comparisons between two groups were conducted in two-tailed using Mann-Whitney tests. Value of $P$ less than 0.05 was considered significant.

\section{Results}

In this study, 180 patients participated in the pulmonary rehabilitation program were included. The 79 patients were excluded from the study. The exclusion criteria were included past medical history of DM $(n=56)$, previous documented IHD $(n=61)$ and clinical evidence of chronic renal failure $(n=13)$ and finally, 101 patients were evaluated (78 male and 23 female). Mean ages of the participants were $59.98 \pm 15.92$ and $51.88 \pm$ 
19.04 in the Cor pulmonale and non-Cor pulmonale groups, respectively. There were no significant differences in the gender and age between two groups ( $P>0.05)$. Mean BMls of the patients with Cor pulmonale and without Cor pulmonale were $19.14 \pm 3.6$ and $21.08 \pm 2.54$, respectively and difference between two groups was significant $(p<0.05)$.

The characteristics of each group (mean \pm SD) as well as statistical differences between two groups are shown in Table 1. In the echocardiography study, mean Systolic Pulmonary Arterial Pressure (SPAP) in the Cor pulmonale and non-cor pulmonale groups were $48.64 \pm 10.42 \mathrm{mmHg}$ and $32.24 \pm 4.10 \mathrm{mmHg}$, respectively and SPAP difference between two groups was significant $(p<0.05)$. In the spirometry study, mean $\mathrm{FEV}_{1} / \mathrm{FVC}$ in the patients with and without cor pulmonale were $49.1 \pm 4.3$ and $61.34 \pm 7.8$, respectively. Besides, mean of $\mathrm{FEV}_{1}$ in percent in the subjects with and without cor pulmonale were predicted to be $37.22 \pm 4$ and $41.4 \pm 11.2$, respectively. Considering to both $\mathrm{FEV}_{1} / \mathrm{FVC}$ and $\mathrm{FEV}_{1}$ measurements, the difference between two groups was significant $(p<0.05)$. It should be noted that the spirometry data may include bias that includes poor patient effort in the maneuver required for the measurement of lung function. Anthropometric data might also reduce confounding in the investigating relation.

Results of the 6MWT in the mentioned groups are shown in the Table 1. The mean of the traveled distances (in meter) during the test were $264.85 \pm 114.1$ and $344.13 \pm 84.19$ in the cor pulmonale and non-cor pulmonale groups, respectively. The difference between the groups was significant $(p<0.001)$. Oxygen desaturation (in percent) in the cor pulmonale and noncor pulmonale patients were $8.71 \pm 6.41$ and $7.90 \pm 6.80$, respectively. The differences between the groups was not significant $(P=0.351)$.

Table 1: The characteristics of the patients in cor pulmonale and non-cor pulmonale group.

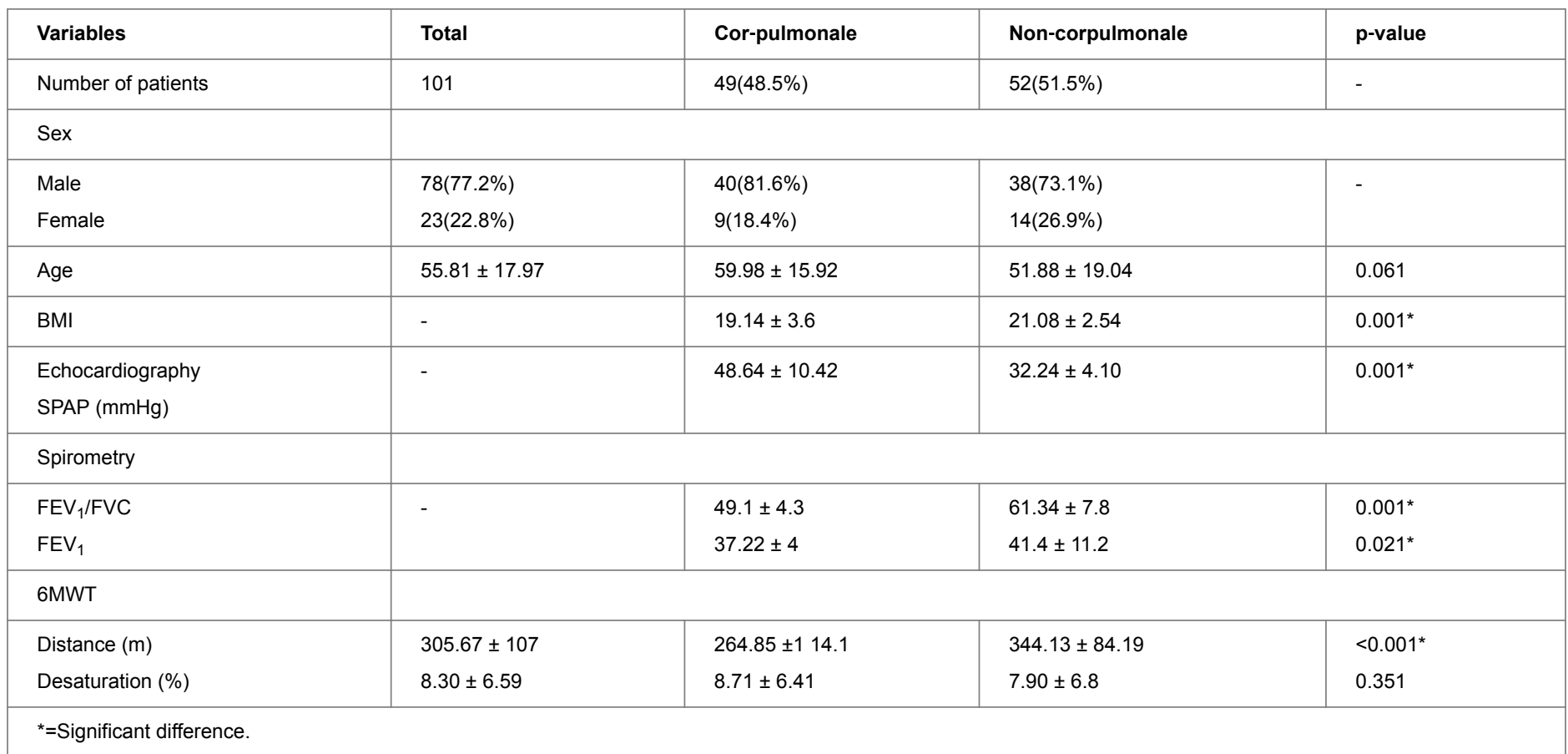

\section{Discussion}

The purpose of the current report was to study the differences in the FC and amount of the oxygen desaturation during 6MWT on the COPD participants with and without evidence of cor pulmonale. The results showed that there were significant differences in the BMI, pulmonary function test and pulmonary artery pressure estimated by echocardiography between the cor pulmonale and non-cor pulmonale groups. Furthermore, the distances travelled by the cor pulmonale subjects during 6MWT are significantly less than the non cor pulmonale. However, the decrease in $\mathrm{SPO}_{2}$ was seen in both groups, but there was no significant difference in the amount of the oxygen desaturation between two groups.

It has been shown that the incidence of PHtn increases as the COPD worsens [22,23]. Vascular remodeling secondary to chronic hypoxemia, inflammation and loss of the vascular bed in emphysematous state are the main causes for increasing the pulmonary artery pressure in the COPD patients [24]. Unfortunately, studies about the impact of cor pulmonale on FC in COPD patients are really limited. Most of studies are based on CPET, which is a sensitive test that could explain the pattern of expired gas in different cardiopulmonary diseases [25]. In a study based on the 6MWT, it was shown that the distance covered during six minutes was significantly lower in the cor pulmonale subjects compared to non-cor pulmonale COPD patients [24]. In some studies, the average distance traveled in patients suffering from COPD is reported to be between 283 to 388 meters and vary depending on the severity of the disease $[26,27]$. However, different variables such as ethnicity, height, weight, BMI and muscle mass, level of education and the presence of underlying disease influence the results of 6MWT [28]. The results of the current study showed that distance traveled by the patients without evidence of cor pulmonale is 
considerably more than the subjects without any evidence of cor pulmonale. This difference may be due to the differences between the BMls of two groups. Agrawal et al studied the demographic characteristics (such as BMIs) of COPD patients that were in different stages of the disease [29]. In their study, there was a significantly reverse correlation between the severity of COPD and BMI. The lower BMI in the cor pulmonale group could explain the lower distance travelled during the 6MWT. Measuring the oxygen saturation during the 6MWT was not been accepted as a standardized procedure [15] until Takigawa et al. discussed the importance of the oxygen saturation monitoring during 6MWT for the first time [17].

Casanova et al showed the role of the distance travelled and oxygen desaturation during 6MWT on survival of COPD patients [16]. Travelled distances lower than 340 meters and oxygen drop more than $6 \%$ in COPD patients were demonstrated to be associated with the worst prognosis. As far as we know, to date, the impact of cor pulmonale on oxygen desaturation during the 6MWT has not been studied. Oxygen desaturation is a common phenomenon in COPD patients during exercise. The main cause of hypoxemia in COPD is ventilation/perfusion (V/Q) mismatch secondary to progressive airflow obstruction and destruction of the pulmonary vessels which increased by diseases progression $[30,31]$. Holverda et al studied the result of utilizing of CPET on COPD patients with and without evidence of secondary PHtn [25]. Oxygen desaturation was observed in both groups, and the oxygen loss in the group with increased pulmonary pressure was significantly more than another group. The findings of Holverda et al. were in contrast to the results of the current study. This controversy may be related to the difference in the quality of tests that were used in two studies. The exercise test in the current research was self-paced and not sensitive and accurate as CPET. The differences in the results of two studies could be explained by the fact that oxygen desaturation in COPD patients is multifactorial.

There are other factors and variables that might explain our findings that include asthma history, tobacco use, gender effect, air pollution, indoor cooking practices, occupational exposures that effect the respiratory system, and genetic or host factors that predispose a study subject to developing COPD and cor pulmonale.

One of limitations of the current study was the employing of traditional and old device to measure oxygen saturation during the 6MWT. Nowadays, utilizing the portable CPET devices during the 6MWT is on the rise. Such devises have a low weight and give a lot of information about the underling mechanism of hypoxemia during 6MWT.

Another limitation of this study was the using of BMI instead of subjects muscle mass variable. In order to the weight changes that results from peripheral edema in cor pulmonal subjectse, using the BMI does not seem logical. The use of muscle mass variable, which could be obtained by special instruments, can eliminate such errors and give useful information about the muscle fibers.

\section{Conclusion}

Considering the results of this study, there is significant difference in BMI, pulmonary function test and pulmonary artery pressure estimated by echocardiography between the cor pulmonale and non-cor pulmonale groups. Moreover, the distance travelled by the cor pulmonale subjects during the test was significantly less than non-cor pulmonale patients. However, despite of the decreasing in the oxygen saturation in both groups, no significant difference was seen in the amount of desaturation between two groups.

\section{Acknowledgement}

Authors would like to thank all colleagues at Masih Daneshvari Hospital that helped with preparation of this manuscript.

\section{References}

Lozano R, Naghavi M, Foreman K, Lim S, Shibuya K, et al. (2013) Global and regional mortality from 235 causes of death for 20 age groups in 1990 and 2010: A systematic analysis for the Global Burden of Disease Study 2010. Lancet 380: 2095-2128.

2. Varmaghani M, Farzadfar F, Sharifi F, Rashidain A, Moin M, et al. (2016) Prevalence of Asthma, COPD, and Chronic Bronchitis in Iran: A Systematic Review and Meta-analysis. Iran J Allergy Asthma Immunology 15: 93-104.

3. Weitzenblum E, Chaouat A (2009) Cor pulmonale. Chronic Respi Dise 6: 177-185.

4. Carbone R, Bossone E, Bottino G, Monselise A, Rubenfire M (2004) Secondary pulmonary hypertension-diagnosis and management. Eur Rev Medical Pharmacol Sci 9: 331-342.

5. Thabut G, Dauriat G, Stern JB, Logeart D, Lévy A, et al. (2005) Pulmonary hemodynamics in advanced COPD candidates for lung volume reduction surgery or lung transplantation. Chest 127: 1531-1536.

6. Weitzenblum E (2003) Chronic cor pulmonale. Heart 89: 225-230.

Han MK, McLaughlin VV, Criner GJ, Martinez FJ (2007) Pulmonary diseases and the heart. Circulation 116(25):2992-3005.

8. Bishop JM, Cross KW (1983) Physiological variables and mortality in patients with various categories of chronic respiratory disease. Bull Eur Physiopathol Respir 20: 495-500.

9. Traver GA, Cline MG, Burrows B (1979) Predictors of mortality in chronic obstructive pulmonary disease: A 15-year follow-up study 1-3. Am Review Respir Dise 119: 895-902.

10. Park YM, Chung WJ, Lee SP, Choi DY, Baek HJ, et al. (2014) Efficacy of Inhaled lloprost in cor pulmonale and severe pulmonary hypertension associated with tuberculous destroyed lung. J Cardiovascular Ultrasound 22: 95-97.

11. Kessler R, Faller M, Fourgaut G, Mennecier B, Weitzenblum E (1999) Predictive factors of hospitalization for acute exacerbation in a series of 64 patients with chronic obstructive pulmonary disease. Am J Respir Crit Care Med 159: 158-164.

12. ATS statement: Guidelines for the six-minute walk test (2002) Am J Respir Crit Care Med 166: 111-117.

13. Schaufelberger $M$, Swedberg $K$ (1998) Is 6-minute walk test of value in congestive heart failure? Am Heart J 136: 371-372. 
14. Paciocco G, Martinez F, Bossone E, Pielsticker E, Gillespie B, et al. (2001) Oxygen desaturation on the six-minute walk test and mortality in untreated primary pulmonary hypertension. Eur Respir J 17: 647-652.

15. ATS Committee (2002) ATS statement: Guidelines for the sixminute walk test. Am J Respir Crit Care Med 166: 111-117.

16. Casanova C, Cote C, Marin JM, Pinto-Plata V, de Torres JP, et al. (2008) Distance and oxygen desaturation during the 6-min walk test as predictors of long-term mortality in patients with COPD. Chest 134: 746-752.

17. Takigawa N, Tada A, Soda R, Date H, Yamashita M, et al. (2007) Distance and oxygen desaturation in 6-min walk test predict prognosis in COPD patients. Respir Med 101: 561-567.

18. Moreira MÂF, Medeiros GAd, Boeno FP, Sanches PRS, Silva Júnior $D P$, et al. (2014) Oxygen desaturation during the six-minute walk test in COPD patients. J Bra Pneumol 40: 222-228.

19. Holland AE, Dowman L, Fiore J, Brazzale D, Hill CJ, et al. (2014) Cardiorespiratory responses to 6-minute walk test in interstitial lung disease: Not always a submaximal test. BMC Pulm Med 14: 136.

20. Holland AE, Spruit MA, Troosters T, Puhan MA, Pepin V, et al. (2014) An official European Respiratory Society/American Thoracic Society technical standard: Field walking tests in chronic respiratory disease. Eur Respir J 44: 1428-1446.

21. Singh SJ, Puhan MA, Andrianopoulos V, Hernandes NA, Mitchell $\mathrm{KE}$, et al. (2014) An official systematic review of the European Respiratory Society/American Thoracic Society: Measurement properties of field walking tests in chronic respiratory disease. Eur Respir J 44: 1447-1478.

22. Mitchell RS, Vincent TN, Ryan S, Filley GF (1964) Chronic obstructive bronchopulmonary disease-IV. The clinical and physiological differentiation of chronic bronchitis and emphysema. Am J Med Sci 247: 513-521.
23. Renzetti AD, McClement JH, Litt BD (1966) The Veterans Administration cooperative study of pulmonary function: III. Mortality in relation to respiratory function in chronic obstructive pulmonary disease. Am J Med 41: 115-129.

24. Chaouat A, Naeije R, Weitzenblum E (2008) Pulmonary hypertension in COPD. Eur Respir J 32: 1371-1385.

25. Holverda S, Bogaard HJ, Groepenhoff H, Postmus PE, Boonstra A, et al. (2007) Cardiopulmonary exercise test characteristics in patients with chronic obstructive pulmonary disease and associated pulmonary hypertension. Respir 76: 160-167.

26. Rasekaba T, Lee A, Naughton M, Williams T, Holland A (2009) The six-minute walk test: A useful metric for the cardiopulmonary patient. Inter Med J 39: 495-501.

27. Alameri $\mathrm{H}, \mathrm{Al}$-Majed S, Al-Howaikan A (2009) Six-min walk test in a healthy adult Arab population. Respir Med 103: 1041-1046.

28. Iwama AM, Andrade GND, Shima P, Tanni SE, Godoy ID, et al. (2009) The six-minute walk test and body weight-walk distance product in healthy Brazilian subjects. Braz J Med Bio Res 42: 10801085.

29. Agrawal SR, Joshi R, Jain A (2015) Correlation of severity of chronic obstructive pulmonary disease with health-related quality of life and six-minute walk test in a rural hospital of central India. Lung India 32: 233-240.

30. Barbera JA, Ramirez J, Roca J, Wagner PD, Sanchez-Lloret J, et al. (1990) Lung structure and gas exchange in mild chronic obstructive pulmonary disease. Am Rev Respir Dis 141: 1-4.

31. Sandek K, Bratel T, Hellström G, Lagerstrand L (2001) Ventilationperfusion inequality and carbon dioxide sensitivity in hypoxaemic chronic obstructive pulmonary disease (COPD) and effects of 6 months of long-term oxygen treatment (LTOT). Clin Physiol 21: 584-593. 